\title{
O CORDÃO DA BICHARADA: A ESPETACULARIDADE DO CARNAVAL DE RUA EM JUABA-CAMETÁ/PA
}

\author{
THE CORD OF BICHARADA: THE SPECTACULARITY OF
}

THE STREET CARNIVAL IN JUABA-CAMETÁ/PA

\section{Ivone Maria Xavier de Amorim Almeida ICA/UFPA}

\section{Resumo}

Este artigo é resultante das coletas de dados realizadas na localidade de Juaba, na cidade de Cametá no período de 2018-2019¹ , vinculadas ao projeto "Festas, Brincadeiras, cortejos, procissões e Atos Devocionais: estudos sobre manifestações populares na Amazônia paraense", cujo objetivo se centra na investigação da atuação dos brincantes no cordão da bicharada no carnaval de Juaba. O Cordão da Bicharada é considerado um bloco carnavalesco que homenageia a fauna da Amazônia através do uso de fantasias confeccionadas pelos moradores locais. A apresentação do cordão da bicharada é marcada pelo entusiasmo e alegria dos participantes e com uma visualização estética totalmente peculiar. Toda a fundamentação teórica utilizada na construção dos argumentos reflexivos sobre o tema advém da etnocenologia, acionando as categorias conceituais espetacularidade e teatralidade como mote na compreensão da participação dos integrantes no cordão da bicharada.

\section{Palavras-chave:}

Cordão da bicharada; Etnocenologia;

Espetacularidade; Teatralidade.

\section{À GUISA DE UMA INTRODUÇÃO}

O município de Cametá é o mais antigo e tradicional dos baixos rios do Tocantins, pela sua importância histórica empresta seu nome à antiga microrregião de Cametá. Com uma história interessante, Cametá passou à categoria de Patrimônio Histórico Nacional pela lei n 7537 , de 16 de setembro de 1986 pela sua notável tradição histórica. A cidade de Cametá é considerada uma das municipalidades mais antigas do Estado

\section{Abstract}

This article is the result of data collection sums carried out in the city of Juaba, in the city of Cametá in the period 2018-2019, linked to the project "Parties, Games, processions, processions and Devotional Acts: studies on popular manifestations in the Amazon of Pará", whose objective focuses on the investigation of the participation of pranksts in the cordon of bicharada in the Juaba carnival. Cordão da Bicharada is considered a carnival block that honors the fauna of the Amazon through the use of costumes made by local residents. The presentation of the bicharada cord is marked by the enthusiasm and joy of the participants and with a totally peculiar aesthetic visualization. All the theoretical foundation used in the construction of reflexive arguments on the theme comes from ethnocenology, triggering the conceptual categories spectacularity and theatricality as a motto in the understanding of the participation of the members in the cord.

Keywords:

Bicharada cord; Ethnocenology;

Spectacularity; Theatricality.

do Pará. Sendo instituída em 1620, pelo Frade Capuchinho Cristóvão José, à margem esquerda do rio Tocantins, onde habitavam os índios Camutás, que moravam em casas nos topos das árvores, a cidade cametaense também recebe uma definição em Tupi como "degrau do mato".

Atualmente, Cametá possui 10 distritos, a saber: Distrito-sede, Juanacoeli, Curuçambaba, Carapajó, Moiraba, Vila do Carmo do Tocantins, Areião, Juaba, Torres de Cupijó e Porto Grande. 
Esses distritos historicamente trazem importantes contribuições econômicas e Culturais à região tocantina. A comunidade de Juaba ascendeu à condição de vila distrital através da Lei no 1530 de 05 de outubro de 1916. Como Vila Distrital, Juaba comporta um conjunto de comunidades quilombolas, formado pelos quilombos do Mola, Porto Alegre, Laguinho e Tomázia.

De acordo com Gomes (2006), o Distrito do Juaba apresenta extrema importância para Cametá, através da produção de farinha e de outros derivados oriundos do plantio da mandioca, cuja logística é realizada pelos próprios ribeirinhos, que agenciam $\mathrm{o}$ beneficiamento comercial da farinha para o município tocantino. Toda produção das comunidades quilombolas é comercializada no próprio Distrito ou Vila do Juaba, que nessa perspectiva recebem compradores das regiões próximas e, sobretudo de Cametá.

A importância do Rio Tocantins no município de Cametá, e particularmente na vila distrital de Juaba, é enfatizada pela ligação que essas localidades mantêm com inúmeros furos, além dos igarapés e braços de rios, que se interpenetram nas dezenas de ilhas que compõem povoados e aglomerações relativamente habitados.

O Município de Cametá - assim como toda região tocantina - é rico em manifestações populares, como as festas de devoção a santos do catolicismo popular, festas juninas e também as de carnaval. Aliás, o carnaval de Cametá é conhecido nos sites de turismo como o "carnaval das águas", expressão usual que marca a circulação, na região das ilhas, de embarcações com brincantes e foliões caracterizados de bichos da fauna local e de tantos outros que compõem o imaginário fantástico da Amazônia paraense. Mas é importante considerar que o carnaval em Cametá não se restringe à estética do carnaval das áquas. É frequente o desfile das escolas de samba, os bailes à fantasia nos clubes locais, e os grupos de Fofós que, no período de momo, se concentram na praça da Cultura para a batalha da maizena.

Também na vila de Juaba existe o carnaval do "Cordão da Bicharada" - bloco carnavalesco que homenageia os animais da Amazônia simbolicamente representados pelos personagens de animais, com participações de moradores locais - adultos e crianças. 0 colorido das fantasias, 0 ato performático desenvolvido pelo corpo-brincante e a alegria contagiante gera uma visualização estética capaz de agradar aqueles que assistem à evolução do cordão da bicharada, na condição de expectadores.

A estrutura organizativa deste artigo parte de uma reflexão epistemológica na área da Etnocenologia, para descrever o cortejo do cordão da bicharada e seus elementos estéticos no campo conceitual da teatralidade e da espetacularidade. Ao lado destas questões, o artigo também procura revelar o envolvimento dos brincantes do cortejo.

\section{O CORDÃO DA BICHARADA EM JUABA}

o Cordão da Bicharada do Juaba, segundo seu precursor e idealizador, mestre Zenóbio Ferreira², tem sua origem no seu imaginário infantil, quando ouvia histórias que seu pai, Raimundo Inácio Ferreira (seu Mimico), Ihe contava sobre os animais e o meio ambiente onde vivia. Também se inspirou nos livros que leu em sua infância, particularmente, de uma frase lida em um desses antigos livros e nunca esqueceu. Sobre essa memória, seu Zenóbio diz:

Estava lendo um livro, no qual tinha uma frase que me chamou bastante atenção que dizia assim: 'as aves não tem onde pousar'[...] Passou vários anos, encontrei um livro na biblioteca por nome Mundo Animal que tinha várias figuras de animais. Era animal de tudo que era canto. Foi daí que surgiu a ideia de construir as vestimentas dos animais (MESTRE ZENÓBIO, 2019).

Durante a entrevista, mestre Zenóbio deixou transparecer sua enorme preocupação, já na década de setenta do século $X X$, com o meio ambiente, sobretudo em decorrência das constantes depredações observadas por ele nas regiões das ilhas e na área continental, provocadas por constantes queimadas e desmatamentos. Essa preocupação o levou a "matutar" sobre fazer alguma coisa para alertar o pedido de socorro emitido pela natureza. Foi aí que teve a ideia de criar o cordão da bicharada: "[...] eu queria trazer uma mensagem da floresta para as pessoas, mostrando as dificuldades dos animais com a devastação das matas, com a poluição ambiental e como eles sobrevivem" (MESTRE ZENÓBIO, 2019).

Com o passar do tempo, e diversas apresentações durante vários carnavais, o fundador do cordão acredita que a união entre o homem e natureza foi alcançada. No começo, ele conta que o público ainda 


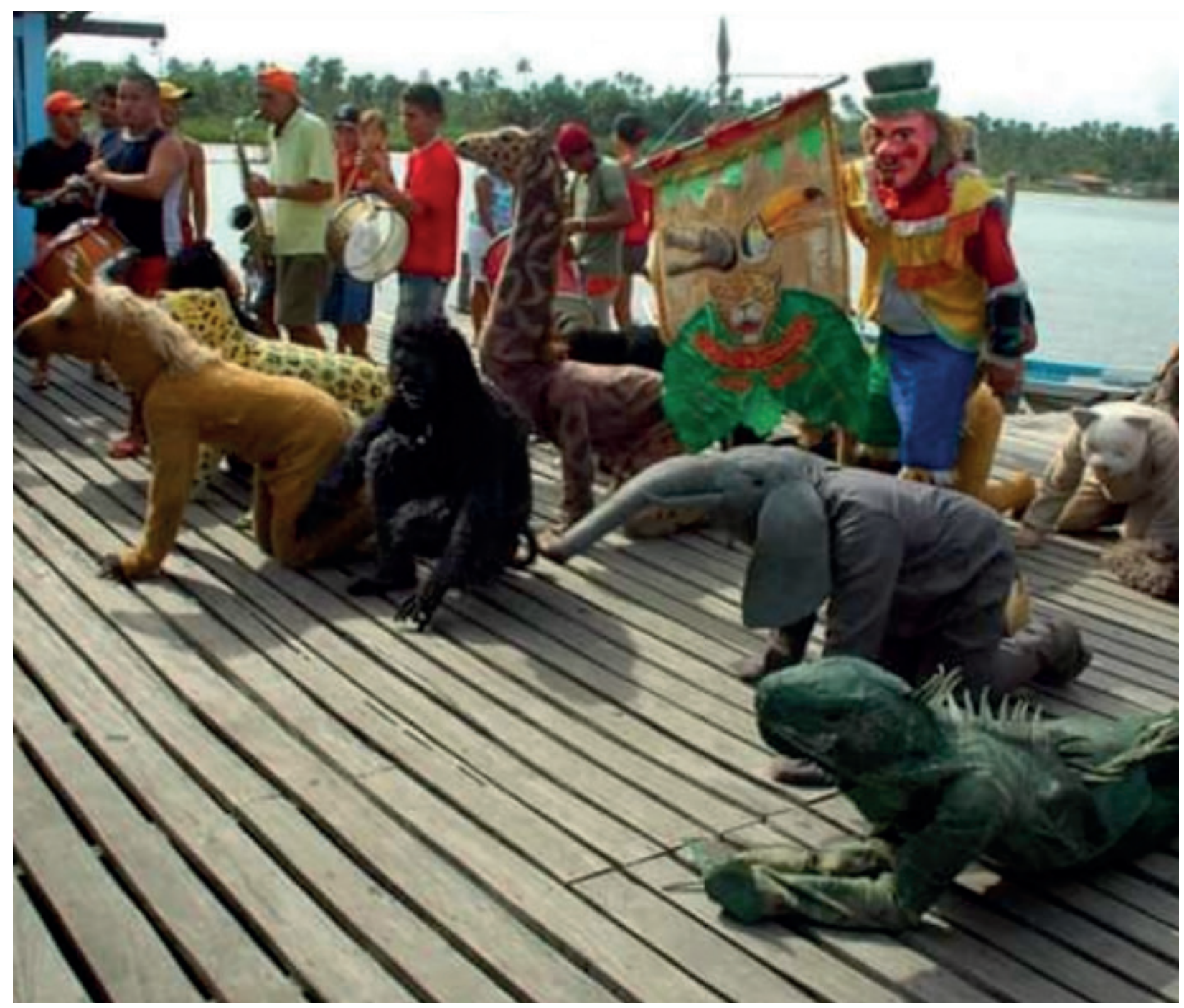

Figura 1 - Foliões caracterizados de bichos e em estado de performance. Fonte: Acervo de Mestre Zenóbio (2010).

se assustava bastante com os animais gigantes que invadiam a cidade para animar a população. Atualmente, segundo ele, é tudo bastante diferente.

\begin{abstract}
Hoje em dia, aonde quer que a gente se apresente, é uma felicidade. Crianças, jovens, adultos e idosos se unem aos bichos. As pessoas tinham medo da gente. Nós tínhamos uma regra de não tirar as máscara e fantasias após o desfile porque queríamos conquistar o povo como bicho e não como gente (Idem).
\end{abstract}

A Bicharada do Juaba é definida por seu fundador como cordão carnavalesco. No Nôvo Diccionário da Língua Portuguêsa, de Candido de Figueiredo, publicado em 1889, há várias definições para a palavra cordão, mas como era de esperar, não há uma definição sobre cordão compreendido como grupo ou manifestação carnavalesca. Figueiredo define cordão como: "corda delgada; fileira; série de postos militares para evitar contágio; objecto ou orgam, que tem semelhança com uma pequena corda" (FIGUEIREDO, 1889, p. 347). Já a versão atualizada do Novo Diccionário da Língua Portuguesa (FIGUEIREDO, 1913), além das definições da versão anterior, aparece também a palavra cordão como manifestação ou grupo carnavalesco. Nesse sentido, a definição de Figueiredo sobre corda é: "certo cortejo ou grupo carnavalesco". O autor destaca que essa definição refere ao Brasil, Rio de Janeiro (FIGUEIREDO, 1913, p. 455). Já no Dicionário do Folclore Brasileiro, de Câmara Cascudo (2012), a definição de cordão é dividida em dois: uma manifestação carnavalesca que, para o autor em uma definição rápida, pode ser entendida como "grupo de foliões com roupas de fantasia, cantando e dançando, mais ou menos ritmicamente"; e uma manifestação de festa religiosa (CASCUDO, 2012, p. 225). 
É pertinente considerar que embora a Bicharada do Juaba seja considerada cordão carnavalesco, ele difere sobremaneira dos cordões carnavalescos existentes nas mais diferentes regiões do Brasil. Em Juaba, ao invés dos foliões representarem através de suas vestimentas, reis, rainhas, bobos da corte, índios, caçadores, as fantasias representam animais dos mais diferentes tamanhos. São várias araras, jacarés, cobras, macacos, jabutis, tucanos, botos e tantos outros que compõem a fauna amazônica, além de outros animais de outros continentes como girafa, urso, hipopótamo. Durante a festa do Momo, este cordão de bichos se apresenta nos trapiches das residências, às margens do Rio Tocantins, ao toque de músicas próprias do grupo, em ritmos de marchinhas e também com o uso de comédias.

Segundo Arnoud (2018), nas apresentações, os animais são os protagonistas de atos performáticos, exibindo-se ao som de marchinhas de carnaval criadas por integrantes do próprio grupo, como seu Raimundo Inácio Ferreira (pai do mestre Zenóbio) e Afonso Aragão. A figura 1 ilustra a chegada do cordão no trapiche de uma das ilhas em Cametá. Nela, é possível observar o condutor do cordão com o estandarte do grupo, a marchinha com instrumentos de sopro e percussão e os animais, performatizados para o início do cortejo.

Durante a apresentação do cortejo, cada animal, ao ser convocado pelo domador caracterizado de palhaço - desenvolve ato performático marcado pela composição estética de caráter espetacular. o corpo que é habitado pelo animal incorpora todo o gestual e som, gerando nos expectadores um clima de euforia, sobretudo quando conseguem identificar um animal que não pertence à fauna local. Ao término das apresentações, cada animal do cordão da bicharada deixa uma mensagem reflexiva sobre a necessidade de preservação do biossistema, posto que: "o objetivo central do grupo está voltado para a conscientização das pessoas para a preservação da natureza e das dificuldades que os animais tem para sobreviver na floresta" (MESTRE ZENÓBIO, 2019). Este ato performático, encenado entre domador e animal, é o ponto alto do cortejo do cordão da Bicharada. Mestre Zenóbio relata que:
Quando chega o momento da comédia (fala dos animais) em forma de círculo, no intervalo de uma música e outra e quando acionado pelo domador, o animal se manifesta em forma de diálogo e fala o boi e o cavalo contando sua trajetória de vida, depois vem o leão se apresentando como rei dos animais que por se considerar o rei da selva, deixa sua mensagem de protesto (Idem).

Cabe ao domador comandar o jogo entre os animais e é interessante perceber que o jogo cênico contido no cordão da Bicharada, ao mesmo tempo em que permite a jocosidade, a brincadeira, também propicia aos expectadores momento reflexivo sobre a necessidade de preservação do meio ambiente, de sua flora e fauna. A seguir algumas comédias dos animais narradas no Cordão

\section{COMÉDIA DO REI LEÃO}

Sou o rei dos animais

A selva é o meu Reinaldo

Como carne todo dia

Gosto muito de veado

Às vezes, também da zebra

E o banquete é adiado

Nas planícies africanas

Eita visão gostosa

O pôr do sol nem se fala

Que coisa maravilhosa

Eu ao lado da rainha

Que é bastante dengosa

[....] amigo palhaço

Eu já vou me retirar

A barriga ronca

Preciso me alimentar

Dê licença

Que a preguiça vou levar

Volto para o meu reinado

E até o outro carnaval.

(Autor: Afonso Aragão)

\section{COMÉDIA DO CAVALO COM O BOI}

- Olá meu amigo boi!

- Sim senhor, amigo cavalo!

- Como é que as coisas vam?

- As coisas vam nesse ritmo desenfreado

das carradas que eu dava ontem, hoje então todas dobradas.

- E você amigo cavalo, o que tem a me dizer?

- Eu só falo em sacrifício, que tenho em meu viver com o peso em minhas costas, chicoteado, vivo a correr.

(Autor: Afonso Aragão) 


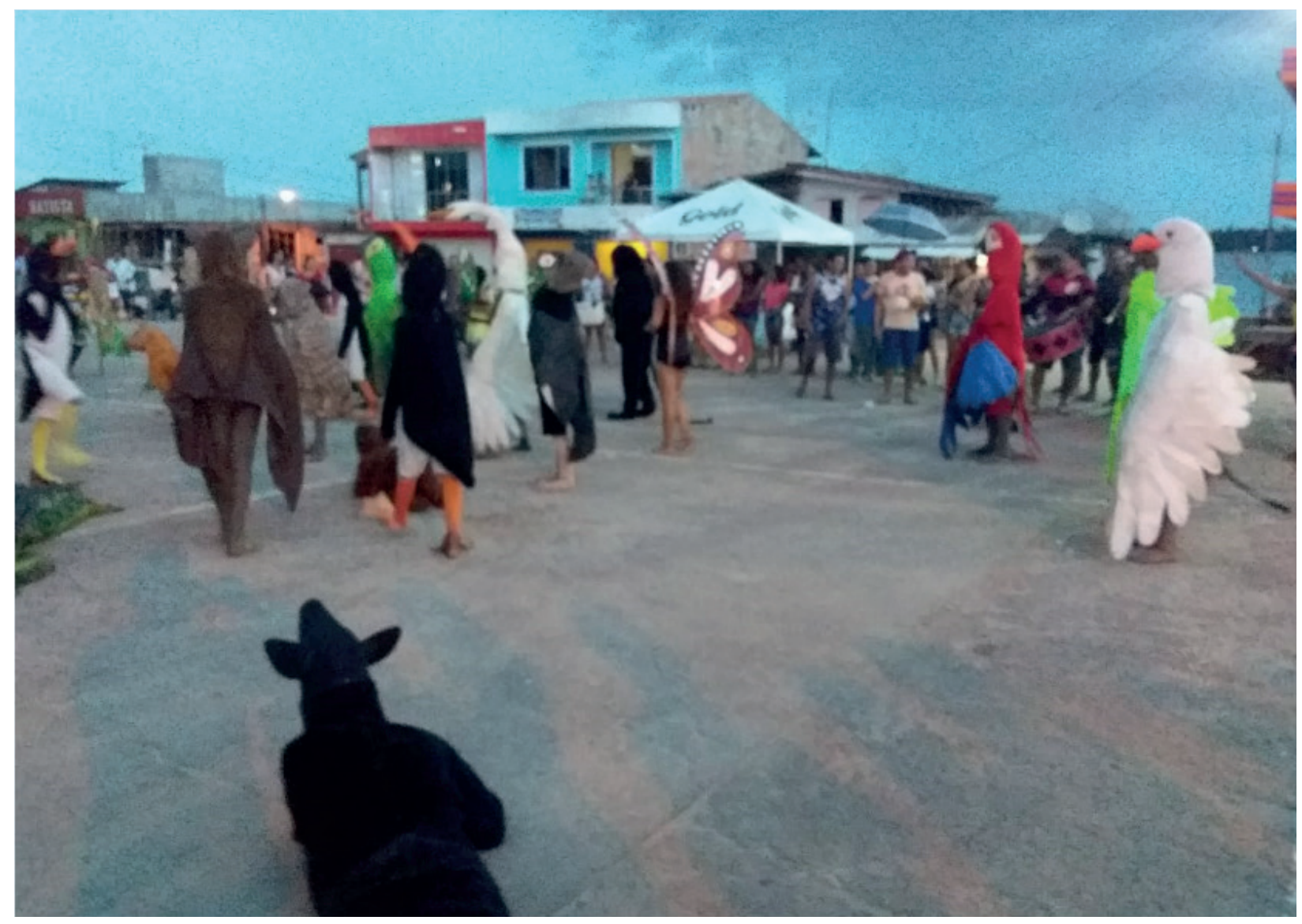

Figura 2 - Brincantes interagindo em espaço aberto. Fonte: acervo Mestre Zenóbio (2016).

\section{COMÉDIA DO BODE}

Eu sou o Bode cheiroso, grande conquistador, Carinhoso e boa pinta, excelente reprodutor, A cabra que se aguente tenho potência e vigor, Já namorei a dona vaca, dona zebra, saracura, Só não namorei a girafa porque não deu certo na altura. Tenho 120 esposas 200 companheiras

E ainda tirei uma casquinha com as comadres/ fofoqueiras.

Porem agora resolvi acabar com essa loucura,

Quem anda com a mulher do outro não tem a vida/ segura,

Cada passo que ele dar tá com o pé na sepultura.

Assim senhoras e senhores, eu já vou me retirar à/ cabra ta me esperando,

Eu não posso demorar

Um adeus Bicharada

E até outro evento popular.

(Autor: Afonso Aragão).

A apresentação dos atos de comédia é carregada de teatralidade, posto que tal conceito significa qualidade daquilo que é teatral ou tem condições para ser apresentado em cena. Neste sentido, quanto mais o brincante carrega no gesto, no movimento do corpo que acentua a identificação do animal em cena, mais o expectador reage com aplausos, risadas e assobios. E é exatamente isso que a etnocenologia define como espetacularidade. Em outras palavras, a etnocenologia se estrutura como uma disciplina especializada no "estudo dos comportamentos humanos espetacularmente organizados" (PRADIER, 1995). Em seu campo investigativo, a palavra espetacularidade assume uma dimensão de primeira grandeza, por se expressar em qualidade do que é espetacular; grandiosidade; ostentação. Sua derivância vem do latim expectare - do ex- "para fora" + spectare - "olhar, observar, contemplar". Nesse sentido, a palavra espetacular está diretamente associada ao que é apresentado para ser contemplado, admirado.

Dentro do cordão da bicharada é permitida a comunicação do personagem animal e o expectador, pois por meio do jogo cênico ocorre a conscientização ao tema real - meio ambiente - causando impacto através da comédia. No 
cordão da Bicharada, a teatralidade é visualmente perceptível no campo das subjetividades, ou seja, na relação íntima que o brincante tem com o cordão. Nas várias apresentações do cordão, que acontecem em várias comunidades das regiões das ilhas, o jogo cênico que se estabelece entre olhante e olhado, é marcado pela interação entre ambos no ato das apresentações. E rapidamente quem está na condição de olhado, passa para olhante e vice versa. Esse jogo cênico de ir e vir, de vir a ser, marca a apresentação do cortejo e estabelece uma conexão forte entre todos os envolvidos neste jogo cênico.

A Sociologia do Cotidiano ou do Drama Social de Erving Goffman também ajuda no exercício de pensar a teatralidade no cordão da Bicharada. Para Goffman, no estudo das representações sociais há que se considerar a perspectiva da representação teatral e os princípios dramatúrgicos, ou seja: a presença do ator, observadores, personagem, espetáculos, desempenho de papéis. Para ele, a representação consiste em "toda atividade de um indivíduo que acontece num período caracterizado por sua presença contínua diante de um grupo de observadores e que tem sobre estes alguma influência" (GOFFMAN, 1989, p. 35). Para que a representação ocorra, é necessário o cenário - partes cênicas de equipamento expressivo - e aparência - estímulos que funcionam no momento de se revelar o status social do ator. Esses elementos são indispensáveis para que no evento ritual ocorra a realização dramática, cuja eficácia é instaurada na presença do outro, de quem assiste o evento. Neste sentido, no cortejo do cordão da Bicharada, o cenário e a aparência são importantes para instaurar a ambiência necessária para a teatralidade. A figura 2 captura um dos muitos momentos de interação entre brincante e expectador.

A estrutura ritual do cordão da Bicharada permite, nos intervalos das apresentações dos animais, que a marchinha entre em cena para tocar suas composições musicais. As letras das músicas se constituem em chamadas reflexivas para todos os participantes do cortejo, por tratarem de temas bem atuais e caros à região Amazônica; a preservação de sua mata, sua fauna e flora. A seguir, algumas letras:
NÃO ESTÁ COM NADA

Quem faz devastação

Refrão: Não está com nada

Zombando da floresta

Fazendo queimada

Não está com nada

Quem não ara a terra

Não está com nada

Quem gosta da guerra

Não está com nada

Quem gosta de droga

Não está com nada

Quem não reparte o pão

Não está com nada

Quem ama a natureza

Também ama a Bicharada

(Autor: Afonso Aragão)

POMBINHA

Pombinha que voa

Pombinha que voa

Não pode parar de voar

Toda a flora destruída

Toda a flora destruída

As aves não podem pousar

Não sei se é flora ou se é devastação

Não sei se é fauna ou se é poluição

Todo homem tem cabeça

Todo homem tem cabeça

Mas não tem bom coração

(Autor: Afonso Aragão)

\section{S.O.S À NATUREZA}

Natureza, natureza!

Sempre foste depredada

Vamos salvar a terra

Protegendo a bicharada

Vamos salvar a terra

Enquanto é tempo

Ta na hora de agir

Pensamento positivo

Não deixa esse tema cair

Faça tudo, meu irmão!

Essa é a razão

Dos nossos ideais

Não destrua as nossas matas

Nossos rios

Nossas cascatas

Proteja os animais

Trate bem da natureza

Com amor e com nobreza

$\mathrm{E}$ os problemas sociais

Meio ambiente

Não se deve poluir

Bote fé nesta mensagem

Fale a mesma linguagem

Vamos todos reflorir.

(Autor: Afonso Aragão) 
As letras destas músicas são de domínio de grande parte dos participantes do cortejo, estejam na condição de brincante ou de expectador.

\section{MESTRE ZENÓBIO E SEUS BICHOS - PROCESSO DE CRIAÇÃO}

Quando mestre Zenóbio decidiu criar o cordão da bicharada, um grande dilema se instaurou, posto que havia necessidade de caracterização dos animais que participariam do cortejo. O artista relata que:

Neste momento, várias perguntas vieram na minha cabeça. Como fazer esses animais, que material podia ser utilizado? Eu já sabia que boa parte do material que fosse usado, tinha que vir da natureza. Era dela que eu tinha que pegar o que precisasse pra criar os animais (MESTRE ZENÓBIO, 2019).

O processo de criação dos bichos começou com esboços em desenhos da cabeça e corpo dos animais. Na construção do primeiro experimento da cabeça, mestre Zenóbio usou o barro como matéria prima, gerando um objeto sem forma definida. Já o segundo experimento de modelagem permitiu ao artista confeccionar a cabeça de um leão, que se tornou naquele momento, o molde para confecção de outras peças.

Conforme o relato do mestre Zenóbio, a maioria dos materiais utilizados na confecção dos animais são: sucatas, peneiros, talas de palmeiras, arame, sobras de tecidos, sacos de lona ou sarrapilheira, papel, isopor, corante feito urucum e carvão. Para colocar sua ideia na rua, ele contou com um grupo de doze pessoas, como informa:

Essas doze pessoas era tudo da comunidade, meus amigos, vizinhos e até parentes. Aí, uns oito tinham habilidade de manusear o material e passaram a compor o grupo de trabalho no barracão, fazendo as cabeças e também na costura dos macacões. As outras três pessoas eram o apoio, a ajuda no corte dos tecidos, no uso das peças para ver os ajustes e até na contação das piadas pra animar o tempo, porque nosso trabalho era a noite (Idem).

A primeira saída do Cordão da Bicharada contou com dezoito fantasias de aninais, dente eles bode, camelo, boi, jacaré, cobra, jabuti. E foi o maior alvoroço:

Quando nós saímos do barracão todos vestidos de bicho, foi surpresa geral. Todos querendo descobrir quem estava vestido daquelas fantasias, mas ninguém tirou. A gente tinha conversado antes que uma vez vestido, vestido até o fim. E é assim até hoje (Idem).
Na contemporaneidade, o Cordão da Bicharada é composto por oitenta e duas (82) fantasias permanentes, ou seja, que foram produzidas pelo coletivo de artesãos do barracão e que saem todos os anos nos desfiles do cordão. Para além dessas oitenta e duas fantasias, o cordão também conta com outras fantasias trazidas por brincantes sazonais e, geralmente, são fantasias comercializadas em larga escala em armarinhos de Cametá.

\section{HOMEM X BICHO - CORPO ALTERADO E METAMORFOSEADO}

No campo etnocenológico, estudos de fenômenos culturais, incluindo o campo das festas, festividades, procissões, atos devocionais dentre outros, a compreensão de comportamentos humanos espetaculares mantém relação íntima com a noção de teatralidade, posto que ambas:

Teatralidade e espetacularidade - o par de categorias ideal-típicas referente à convivência em sociedade; sendo a primeira aplicada às pequenas interações rotineiras, nas quais os indivíduos agem em função do interlocutor (para o olhar do outro, como no sentido etmológico do teatro), de modo mais ou menos consciente e confuso, sem distinção clara entre 'atores e espectadores', por desempenharem, aí, todos, simultaneamente os dois 'papéis'; e a segunda aplicada às maiores interações extraordinárias, quanto coletivamente a sociedade cria fenômenos organizados para o olhar de muitos outros, que dele têm consciência clara como 'atores' ou 'espectadores' (BIÃO, 2009, p. 62).

Para a Etnocenologia o corpo alterado se constitui em categoria conceitual que permite compreender o estado de afetação pelo qual passa o corpo que está envolvido em eventos rituais, os quais se tornam campo investigativo. Nesse sentido, o Cordão da Bicharada, por estar vinculado ao evento ritual carnaval, permite afirmar que a categoria corpo alterado está presente no ato performático dos brincantes durante o cortejo do cordão. 0 estado de corpo alterado pode ser observado em três momentos do cortejo: concentração, apresentação, dispersão. O momento da concentração antecede a apresentação, é quando o brincante veste a fantasia e aquece o corpo com movimentos rítmicos capazes de acionar o estado de corpo do animal vestido. Neste momento é permitida a ingestão de bebidas alcoólicas, dando ao brincante uma espécie de suporte psicológico para suportar o peso e a alta temperatura da fantasia. 0 depoimento a seguir é bastante ilustrativo quando narra que: 


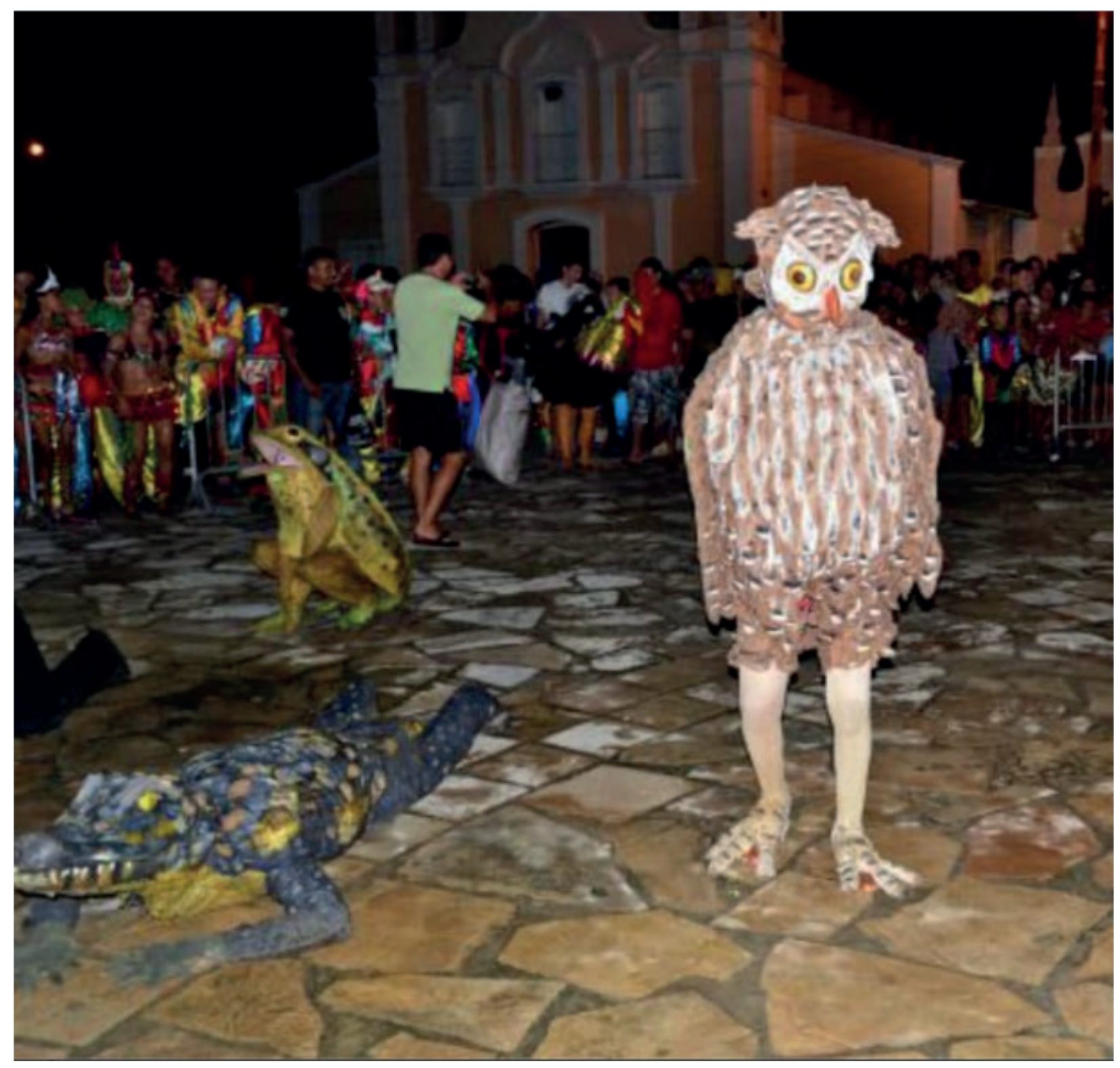

Figura 3 - Momento da apresentação do Cordão da Bicharada. Fonte: arquivo pessoal da autora (2018).

[...] a fantasia é pesada. Essa parte de cabeça que pesa porque é feita a partir de uma armação de arame para dar sustentação. A roupa da fantasia também pesa. Essa aqui é do macaco. A gente primeiro veste o corpo, e antes de colocar a cabeça, vai bem umas geladas pra gente aguentar tudo, porque, depois que veste só tiramos a roupa quando tudo termina (SILVA, 2019) ${ }^{3}$.

$\mathrm{Na}$ apresentação, o corpo do animal fantasiado assume a cena. O som e o movimento corpóreo feito pelo brincante é do jacaré, jabuti, pavão, cobra, arara, tucano, boto, macaco, e tantos outros animais da fauna amazônica ou de outros lugares, como é o caso do camelo, girafa, leão. Neste momento, o brincante deixa de ser ele para dar passagem ao animal performatizado. Durante a apresentação, que dura em média quatro horas, o brincante adulto não poderá tirar nenhuma parte da fantasia, também não poderá atender a chamada de seu nome, muito menos parar de executar os movimentos e sons de seu animal. A figura 3 ilustra os corpos alterados no instante da apresentação.

ParaabrincanteCintiaDias ${ }^{4}$, ocorpoperformatizado do animal, no momento da apresentação, é grandioso, porque: "ao me caracterizar de tucano, percebo que naquele momento, é como se fosse real. Durante as apresentações é como se meu corpo se transformasse, o eu mulher deixo de existir, me sinto livre e leve, como em um passe de mágica não sinto calor nem sede" (DIAS, 2019). 
Já o momento da dispersão, como o próprio nome diz, é o encerramento da apresentação, quando o cordão da bicharada está fora do circuito do evento. É nesta etapa que os corpos dos brincantes voltam à cena. Na maioria das vezes estes corpos saem da condição de brincantes para se tornarem expectadores, quando assistem à exibição de outros blocos de carnaval.

\section{CONSIDERAÇÕES FINAIS}

O Cordão da Bicharada de Juaba já é considerado pelos moradores da localidade como parte indissociável de sua tradição cultural e, também, da cidade de Cametá, uma vez que Juaba pertence a macrorregião deste município paraense.

A exemplo do que acontece com o "Carnaval das águas" de Cametá, que colocou este município no mapa de turismo, o Cordão da Bicharada também tirou Juaba da invisibilidade regional, quando este cordão foi (e ainda é) tema de várias reportagens jornalísticas publicadas nos jornais da cidade de Belém. Essa divulgação, cada vez mais recorrente do carnaval de Juaba, tem oportunizado a instauração do sentimento de pertença junto aos nascidos na comunidade em apreço que cada vez mais, tentam repassar essa valoração do lugar de origem e da cultura local aos seus descendentes.

O recorte analítico realizado na construção deste artigo encontrou amparo na etnocenologia, concentrando o olhar investigativo nas categorias conceituais teatralidade e espetacularidade, posto que, à luz da etnocenologia, tanto teatralidade como espetacularidade se constituem em jogos cênicos presentes tanto no tempo ordinário quanto no extraordinário.

Neste sentido, o processo de construção deste artigo privilegiou a compreensão do Cordão da Bicharada como evento ritual, no campo do extra cotidiano, e seu cortejo sendo marcado por vários sentimentos, expressos na fisionomia daqueles que acompanham o trajeto do cordão na condição de expectadores. O jogo cênico do Cordão da Bicharada se desenvolve através da presença do domador - palhaço $x$ animal. Nas cenas, cabe ao domador apresentar o animal, que por sua vez, se dirige ao centro para iniciar seu ato performático em um primeiro plano, narrando a história de vida, em forma de rima, do animal que se apresenta, para, na sequência, executar os movimentos e sons do animal.
Na contemporaneidade, o Cordão da Bicharada está tão incorporado à cultura local de Juaba e da cidade de Cametá, que comumente é acionado como tema gerador de diferentes disciplinas ministradas nas séries da Escola de Ensino Fundamental de Juaba. Aos recorrentes debates sobre meio ambiente e preservação da natureza que o cordão da Bicharada tem provocado no cotidiano da comunidade e, também, no espaço da sala de aula, soma-se a inculcação da noção de pertencimento. No tempo presente, os moradores de Juaba sentem orgulho de pertencer à comunidade e de possuir o Cordão da Bicharada, que, em certa medida, permitiu colocar a todos e, em particular, seus modos de viver e brincar o carnaval nos circuitos das festas e festividades que acontecem nas várias regiões brasileiras durante a quadra carnavalesca.

\section{NOTAS}

1. Esta coleta de dados oportunizou a escrita de três Trabalho de Conclusão de Curso - TCC, no curso de Licenciatura em Teatro-PARFOR, cujas temáticas voltadas para a cultura local, trataram sobre: o Cordão da Bicharada, de autoria de Elizete Tenório Valente; a Escola de Samba em Cametá, de autoria de Adelciane Alho Ferreira; e a Dança do Negro em Juaba, de autoria de Lonildes Tavares de Carvalho.

2. Natural de Cametá, 73 anos.

3. Carlos Augusto da Silva é brincante do Cordão da Bicharada.

4. Brincante do Cordão da Bicharada.

\section{REFERÊNCIAS}

BIÃO, Armindo. Etnocenologia e a Cena Baiana: textos reunidos. Salvador: P\&G Gráfica e Editora, 2009.

BRIGIDA, Miguel Santa. A etnocenologia na Amazônia. trajetos-projetos-objetos-afetos. Repertório, Salvador, no 25, 2015, p.13-23.

CASCUDO, Luís da Câmara. Dicionário do Folclore

Brasileiro. Editora Global, 2012.

FIGUEIREDO, Candido de. Novo Diccionário da

Língua Portuguêsa. Lisboa: Editora Tavares, vol. II, 1889. 
FIGUEIREDO, Candido de. Novo Dicionnário da Língua Portuguesa. Lisboa: Livraria Clássica Editora, vol. II, 1913.

GOFFMAN, Erving. A representação do eu na vida cotidiana. Petrópolis: Vozes, 1989.

GOMES, F. S. "No labirinto dos rios, furos e igarapés": camponeses negros, memória e pósemancipação na Amazônia, c. XIX-XX. História Unisinos, vol. 10, n³, 2006, p. 281-292.

HOUAISS, Antônio; VILLAR, Mauro de Salles (Org.). Dicionário Houaiss da Língua Portuguesa. Rio de janeiro: Objetiva, 2001.

PRADIER, Jean-Marie. Etnocenologia. In: GREINER, Christine e BIAO, Armindo. (Org.). Etnocenologia: textos selecionados. São Paulo: Annablume,1999.

ROY, Wagner. A invenção da Cultura. Rio de Janeiro: UBU EDITORA, 2017.

SOUSA, Raimundo Valdomiro de. Campesinato na Amazônia: da subordinação à luta pelo poder. Belém: NAEA, 2002.

TAVARES. Luciana P. de O. A Definição do Rural e do Urbano e suas Influências na Implantação de Políticas Públicas: UM ESTUDO DE CASO EM DUAS LOCALIDADES NA CIDADE DE CAMETÁ - PA. Dissertação de Mestrado, Serviço Social, Instituto de Ciências Sociais Aplicadas, Universidade Federal do Pará. Belém, 2009.

\section{ENTREVISTAS}

MESTRE ZENÓBIO. Entrevista. Realizada por Ivone Maria Xavier de Amorim Almeida e Elizete Tenório Valente. Juaba-Pa: em 10 mar. 2019.

SILVA, Carlos Augusto da. Entrevista. Realizada por Ivone Maria Xavier de Amorim Almeida e Elizete Tenório Valente. Juaba-Pa: em 10 mar. 2019.

DIAS, Cintia. Entrevista. Realizada por Ivone Maria Xavier de Amorim Almeida e Elizete Tenório Valente. Juaba-Pa: em 12 mar. 2019,

\section{SOBRE A AUTORA}

Ivone Maria Xavier De Amorim Almeida. Doutora em História Social pela Pontifícia Universidade
Católica de São Paulo (2010); Mestre em Antropologia Social pela Universidade Federal do Pará (1998). É professora Adjunta da Universidade Federal do Pará (UFPA), lotada no Instituto de Ciências das Artes (ICA), vinculada à Escola de Teatro e Dança (ETDUFPA). Compõe o quadro de professores do Programa de Pós-Graduação em Artes em Rede Nacional (UFPA) e do Programa de Pós-Graduação em Artes (Mestrado e Doutorado) PPGARTES-UFPA, vinculada à linha 2 - Artes e Interfaces Epistêmicas. Coordena projeto de Pesquisa "Festas, Brincadeiras, Cortejos, Procissões e Atos Devocionais: Estudos sobre Manifestações populares na Amazônia". Integra - grupo de pesquisa TAMBOR/UFPA/CNPq. E-mails: ivmaxavier@gmail.com e ivone@ufpa.br 